Research Article

\title{
The Impact of Bone Mineral Biomarkers on Cardiac Dysfunction in Predialysis Chronic Kidney Disease Children
}

\author{
Safaa Ali $(\mathbb{D}$, Mohamed Saber $(\mathbb{D}$, and Mohamed Kassem (iD
}

Pediatric Department, Sohag University, Egypt

Correspondence should be addressed to Safaa Ali; safaah003@gmail.com

Received 20 April 2021; Revised 19 June 2021; Accepted 2 August 2021; Published 1 September 2021

Academic Editor: Alessandro Mussa

Copyright @ 2021 Safaa Ali et al. This is an open access article distributed under the Creative Commons Attribution License, which permits unrestricted use, distribution, and reproduction in any medium, provided the original work is properly cited.

\begin{abstract}
Objective. To evaluate the association of bone mineral biomarkers of calcium, phosphorus metabolism, and 25-hydroxy vitamin D with diastolic dysfunction of the left ventricle and left ventricle mass in predialysis chronic kidney children. Patients and Methods. A cross-sectional observational study was conducted on 60 children with chronic kidney disease and treated by conservative treatment from October 2018 to September 2019 in the Pediatric Nephrology and Cardiology Department at our University Hospital. Results. The most common causes of CKD were congenital renal anomalies accounted for 22 (36.67\%) of the studied cases. The mean age of children was $7.05 \pm 2.74$ years, and $32(53.33 \%)$ were males. The children who had a normal diastolic function were $32(53.33 \%)$, while those who had diastolic dysfunction were 28 (46.67\%). There was a statistically significant in serum phosphorus ( $p$ value $=0.03)$, serum PTH $(p$ value $=0.002)$, and hypertension $(p$ value $=0.03)$. There was a statistically significant positive correlation between LVMI and iPTH level $(r=0.89, p \leq 0.0001), 25(\mathrm{OH})$ cholecalciferol $(r=-0.27, p=0.04)$, serum $\mathrm{Ca}(r=-0.37, p=0.004)$, and serum phosphorus $(r=-0.45, p=0.0003)$. Conclusion. Our results revealed that hyperparathyroidism, hyperphosphatemia, and hypertension were significantly associated with diastolic dysfunction while hypovitaminosis D was not significantly associated. Vitamin D deficiency was prevalent in all children with CKD. Biomarkers of mineral bone density were significantly associated with left ventricular hypertrophy and increased left ventricular mass index.
\end{abstract}

\section{Introduction}

Chronic kidney disease (CKD) is a major health problem worldwide in adults and pediatric population. The prevalence of pediatric CKD is 15-74.7 patients per 1 million children [1].

According to the kidney disease improving global outcome (KDIGO) guidelines, CKD is identified by the presence of kidney damage, either structural or functional or, by a decline in glomerular filtration rate (GFR) below $60 \mathrm{ml} / \mathrm{min} / 1.73 \mathrm{~m}^{2}$ of body surface area for more than 3 months [2].

Cardiovascular disease (CVD) is the leading cause of morbidity and mortality among patients with chronic kidney disease [3]. CKD-associated cardiovascular morbidity (CVM) is more commonly reported in the form of diastolic cardiac dysfunction and left ventricular hypertrophy by echocardiography and used as an early marker of CVD. However, the systolic functions are preserved until the late stage $[4,5]$.
Many factors have been implicated in the etiology of the cardiac abnormalities observed in patients with CKD [6]. Recently, interest in the role of vitamin D as it relates to the cardiovascular system increased. Prior studies investigating adult patients with CKD have shown an association between vitamin $\mathrm{D}$ deficiency and the previously mentioned adverse cardiac changes, especially left ventricular hypertrophy [7].

Vitamin D may have cardiovascular effects through several mechanisms. $25(\mathrm{OH}) \mathrm{D}$ is a known regulator of the renin-angiotensin-aldosterone system (RAAS), and treatment with calcitriol leads to renin suppression in experimental studies. Vitamin D receptor is present on vascular smooth muscle cells, and calcitriol can affect the proliferation of these cells [8].

The current study was conducted to assess the cardiovascular changes in children with CKD and detect the association of these changes with markers of calcium and phosphorus metabolism, including 25-hydroxy vitamin D. 


\section{Patient and Method}

The study was a prospective, observational cohort study of pediatric CKD over one year from October 2018 to September 2019. The study was done in the Pediatric Nephrology and Cardiology Department of Sohag University Hospital. The study included 60 children with chronic kidney disease and treated by conservative treatment. The cases were subsequently divided into two groups according to diastolic dysfunction.

Inclusion Criteria: All children (2-18 years) with CKD and treated by conservative (predialysis) treatment were included in this study.

Exclusion Criteria: Patients with primary cardiac disease (e.g., congenital heart disease, congenital anomalies of coronaries or rheumatic heart disease, and cardiomyopathy).

Ethical considerations: Must be complete.

The study was approved by the Institutional Ethics Committee. Informed written consent was obtained from either parent of every included patient.

All patients were subjected to the following:

(1) Full history taking includes demographic data, age, sex, child's previous growth and development, and history about the primary cause of CKD

(2) Clinical examination including the following:

(a) Anthropometric measurements for assessment of nutritional and developmental status included: weight and height

(b) Body mass index (BMI) percentile- $(<5 \%, 5 \%-$ $85 \%$, and $\geq 85 \%)$. Height and body mass index (BMI; $\mathrm{kg} / \mathrm{m}^{2}$ of height) percentiles by age and sex were calculated from tables provided by the Centers for Disease Control and Prevention

BMI was calculated by the following formula: $B M I=W$ eight $(\mathrm{kg}) /($ height $[\mathrm{m}])$

(c) Vital signs, especially arterial blood pressure

(3) Routine laboratory investigations including the following:

(a) Complete blood count (CBC) by an automated analyzer

Anemia was defined as a mean hemoglobin value $<11 \mathrm{~g} / \mathrm{dl}$

(b) Blood urea, blood urea nitrogen, and serum creatinine

(c) Serum albumin and serum electrolytes (ionized calcium, potassium, and phosphorus)

(d) A serum level of $25(\mathrm{OH})$ vitamin $\mathrm{D}$ was measured in a venous blood sample in all included patients. We considered vitamin D "deficiency" if $25(\mathrm{OH})$ D value below $20 \mathrm{ng} / \mathrm{ml}$ and "insufficiency" if $25(\mathrm{OH}) \mathrm{D}$ value between 20 and $30 \mathrm{ng} / \mathrm{ml}$. Vitamin D deficiency was
TABle 1: Distribution of the studied patients according to demographic data and anthropometric measures $(N=60)$.

\begin{tabular}{lc}
\hline Variable & No. $(\%)$ \\
\hline Agelyears & $7.05 \pm 2.74$ \\
Mean \pm SD & $7(2: 13)$ \\
Median (range) & \\
\hline Gender & $28(46.67 \%)$ \\
Female & $32(53.33 \%)$ \\
Male & \\
\hline Weight & $19.43 \pm 7.01$ \\
Mean \pm SD & $18(8: 39)$ \\
Median (range) & $111.57 \pm 18.06$ \\
\hline Height & $113.5(79: 148)$ \\
Mean \pm SD & \\
Median (range) & $14.95 \pm 1.30$ \\
\hline BMI & $15.05(12.8: 17.8)$ \\
Mean \pm SD & \\
Median (range) & $20(33.33 \%)$ \\
\hline BMI & $40(66.67 \%)$ \\
Underweight & $33(55.00 \%)$ \\
Healthy &
\end{tabular}

TABLE 2: Causes and stages of CKD of studied population.

\begin{tabular}{lc}
\hline Variable & No. $(\%)$ \\
\hline Causes of CKD & \\
Congenital renal anomalies & $22(36.7 \%)$ \\
Focal segmental GS & $21(35.00 \%)$ \\
Chronic glomerulonephritis & $11(18.33 \%)$ \\
Chronic interstitial nephritis & $6(10.00 \%)$ \\
\hline Stages of CDK & \\
Stage 3 A & $18(30 \%)$ \\
Stage 3 B & $2(3.33 \%)$ \\
Stage 4 & $40(66.67 \%)$ \\
\hline
\end{tabular}

further classified as severe deficiency $<10 \mathrm{ng} / \mathrm{ml}$ and moderate deficiency $10-20 \mathrm{ng} / \mathrm{ml}$

(e) The glomerular filtration rate (GFR) was estimated using the Schwartz formula [9]

(4) Doppler echocardiography, tissue Doppler imaging, and $M$-mode echocardiography:

Echocardiography was performed in all patients using GE Vivid 9 ((GE Medical System, Horten, Norway, with a 
TABLE 3: The relation between echo finding and diastolic dysfunction.

\begin{tabular}{|c|c|c|c|}
\hline Variable & $\begin{array}{c}\text { Group A } \\
N=32\end{array}$ & $\begin{array}{c}\text { Group B } \\
N=28\end{array}$ & $p$ value \\
\hline \multicolumn{4}{|l|}{ Mean $E / E^{\prime}$} \\
\hline Mean \pm SD & $8.08 \pm 1.31$ & $11.41 \pm 0.58$ & \multirow[t]{2}{*}{$<0.000$} \\
\hline Median (range) & $7.9(6.5: 9.9)$ & $11.25(10.9: 12.4)$ & \\
\hline \multicolumn{4}{|l|}{ Mitral E velocity } \\
\hline Mean \pm SD & $1.01 \pm 0.14$ & $1.11 \pm 0.14$ & \multirow[t]{2}{*}{0.009} \\
\hline Median (range) & $0.98(0.77: 1.19)$ & $1.15(0.92: 1.32)$ & \\
\hline \multicolumn{4}{|c|}{ Lateral mitral annulus $E^{\prime}$} \\
\hline Mean \pm SD & $0.13 \pm 0.02$ & $0.11 \pm 0.02$ & \multirow[t]{2}{*}{$<0.0001$} \\
\hline Median (range) & $0.13(0.1: 0.16)$ & $0.1(0.09: 0.15)$ & \\
\hline \multicolumn{4}{|c|}{ Septal mitral annulus $E^{\prime}$} \\
\hline Mean \pm SD & $0.12 \pm 0.02$ & $0.09 \pm 0.02$ & \multirow[t]{2}{*}{0.0001} \\
\hline Median (range) & $0.12(0.08: 0.14)$ & $0.09(0.06: 0.12)$ & \\
\hline \multicolumn{4}{|l|}{ MV E/A ratio } \\
\hline Mean \pm SD & $1.53 \pm 0.26$ & $1.53 \pm 0.25$ & \multirow[t]{2}{*}{0.87} \\
\hline Median (range) & $1.54(1.3: 2.03)$ & $1.46(1.16: 2)$ & \\
\hline
\end{tabular}

3.5 $\mathrm{MHz}$ multifrequency transducer) to evaluate cardiac structure and function by senior echocardiographer.

(a) Left ventricular mass index (LVMI) is a parameter used in echocardiography and cardiac MRI which is used to evaluate LV hypertrophy. Left ventricular mass (LVM) was calculated using the measurements obtained by two-dimensional $M$-mode echocardiography according to the American Society of Echocardiography (ASE) criteria. Indexed LVM (LVMI) was calculated using the following equations: LVMI = LVM (left ventricular mass)/body surface area or dividing the LVM by height raised to a power of $2.7\left(\mathrm{~g} / \mathrm{m}^{2.7}\right)$ using the formula devised by De Simone et al. [10].

(b) Diastolic function was assessed by both Doppler echocardiography and tissue Doppler imaging. Early mitral inflow velocity $(E)$ and late mitral inflow velocity (A) were measured by Doppler echocardiography. Tissue velocity imaging (TVI) was done in the fourchamber view with the mitral annular planes perpendicular to the ultrasound beam. A $5 \mathrm{~mm}$ pulsed TD sample volume was placed at the septal and lateral aspects of mitral annulus as well as at the lateral aspect of tricuspid annulus. Early diastolic $\left(e^{\prime}\right)$ (early diastolic filling velocity) and late peak diastolic myocardial $\left(a^{\prime}\right)$ peak mitral annular velocities were measured at the medial and lateral mitral annulus using tissue Doppler. The $e^{\prime} / a^{\prime}$ ratio at both annuli was calculated. The peak early mitral annular velocity $\left(E^{\prime}\right)$ was computed as the average of the velocities at the medial and lateral annuli. Using these measurements, the ratio of Doppler-derived peak early mitral
TABLE 4: The relation between diastolic dysfunction, patient characteristic, and anthropometric measurements of children with CKD.

\begin{tabular}{|c|c|c|c|}
\hline Variable & $\begin{array}{c}\text { Group A } \\
N=32\end{array}$ & $\begin{array}{c}\text { Group B } \\
N=28\end{array}$ & $p$ value \\
\hline \multicolumn{4}{|l|}{ Agelyears } \\
\hline Mean \pm SD & $7.23 \pm 2.58$ & $6.89 \pm 2.94$ & 0.58 \\
\hline Median (range) & $7(3: 12)$ & $7(2: 13)$ & \\
\hline \multicolumn{4}{|l|}{ Gender } \\
\hline Female & $16(50.00 \%)$ & $12(42.86 \%)$ & 0.58 \\
\hline Male & $16(50.00 \%)$ & $16(57.14 \%)$ & \\
\hline \multicolumn{4}{|l|}{ Consanguinity } \\
\hline Negative & $17(53.13 \%)$ & $10(35.71 \%)$ & 0.18 \\
\hline Positive & $15(46.88 \%)$ & $18(64.29 \%)$ & \\
\hline \multicolumn{4}{|l|}{ Weight } \\
\hline Mean \pm SD & $19.42 \pm 6.90$ & $19.43 \pm 7.26$ & 0.93 \\
\hline Median (range) & $18(10: 33)$ & $18.5(8: 39)$ & \\
\hline \multicolumn{4}{|l|}{ Height } \\
\hline Mean \pm SD & $111.78 \pm 17.98$ & $111.32 \pm 18.48$ & 0.77 \\
\hline Median (range) & $112(84: 141)$ & $113.5(79: 148)$ & \\
\hline \multicolumn{4}{|l|}{$B M I$} \\
\hline Mean \pm SD & $14.93 \pm 1.31$ & $14.98 \pm 1.32$ & 0.89 \\
\hline Median (range) & $14.75(12.9: 17.6)$ & $15.2(12.8: 17.8)$ & \\
\hline \multicolumn{4}{|l|}{ BMI group } \\
\hline Healthy & $10(31.25 \%)$ & $10(35.71 \%)$ & 0.71 \\
\hline Underweight & $22(68.75 \%)$ & $18(64.29 \%)$ & \\
\hline
\end{tabular}


TABLE 5: The relation between diastolic function, causes, stages, blood pressure, and GFR.

\begin{tabular}{lcc}
\hline Variable & Group A & Group B \\
& $N=32$ & $10(35.71 \%)$ \\
\hline Congenital renal anomaly & $12(37.50 \%)$ & $10(35.71 \%)$ \\
Focal segmental GN & $11(34.38 \%)$ & $5(17.86 \%)$ \\
Chronic glomerulonephritis & $6(18.75 \%)$ & $3(10.71 \%)$ \\
Chronic interstitial nephritis & $3(9.38 \%)$ & \\
\hline Blood pressure & & $4(14.29 \%)$ \\
Normotensive & $17(53.13 \%)$ & $24(85.71 \%)$ \\
Hypertensive & $15(46.88 \%)$ & $28.52 \pm 9.34$ \\
\hline GFR & & $30.9(11.5: 47.5)$ \\
Mean \pm SD & $25.03 \pm 11.19$ & \\
Median (range) & $20.2(11: 55)$ & $13(46.43 \%)$ \\
Stages of CKD & & $1(3.57 \%)$ \\
Stage 3 A & $5(15.63 \%)$ & $14(50.00 \%)$ \\
Stage 3 B & $1(3.13 \%)$ & \\
Stage 4 & $26(81.25 \%)$ & $14(50.00 \%)$ \\
\hline Stages of CKD & & $14(50.00 \%)$ \\
Stage 3 A/B & $6(18.75 \%)$ & 0.002 \\
Stage 4 & $26(81.25 \%)$ & 0.03 \\
\hline
\end{tabular}

inflow velocity to tissue Doppler-derived peak early mitral annular velocity ( $E / E^{\prime}$ ratio) was calculated. Diastolic dysfunction was graded as follows: grade 0 , no diastolic dysfunction; grade 1 (impaired relaxation), $E / E^{\prime} \leq 8$; grade 2 (pseudonormal), $E / E^{\prime}$ 9-12; and grade 3 (restrictive grade) $E / E^{\prime} \geq 13$ [11].

(c) Myocardial performance index (MPI), or Tei index, is a Doppler echocardiographic parameter defined as the sum of the isovolumic contraction and relaxation times divided by the ejection time. It is considered a reliable parameter for evaluating left ventricular systolic and diastolic dysfunction

\section{Statistical Analysis}

The collected data were coded, processed, and analyzed using the SPSS (Statistical Package for Social Sciences) version 22 for Windows ${ }^{\circledR}$ (IBM SPSS Inc, Chicago, IL, USA). Data were tested for normal distribution using the Shapiro Walk test. Qualitative data were represented as frequencies and relative percentages. Chi-square test is used $\left(\chi^{2}\right)$ to calculate the difference between two or more groups of qualitative variables. Quantitative data were expressed as mean \pm SD (standard deviation). Independent samples $t$-test was used to compare between two independent groups of normally distributed variables (parametric data). $p$ value $<0.05$ was considered significant.

\section{Results}

A prospective observational study was done over 12 months, from October 2019 to September 2020. The study was conducted on 60 patients with chronic kidney disease (stage 3 or 4 ), and their age range from 2 to 13 years with a mean value of $7.05 \pm 2.74$ years. They were $32(53.33 \%)$ males and $28(46.67 \%)$ females. The mean weight was $19.43 \pm 7.01$ kilograms ranging from 8:39 kilograms. The mean height was $111.57 \pm 18.06 \mathrm{~cm}$ ranging from $79: 148 \mathrm{~cm}$. The mean body mass index was $14.95 \pm 1.30$ $\mathrm{kg} / \mathrm{m}^{2}$ ranging from $12.8: 17.8 \mathrm{~kg} / \mathrm{m}^{2} .40(66.67 \%)$ of the studied patient was healthy, and 20 (33.33\%) of them was underweight (Table 1).

The most common causes of CKD were congenital renal anomalies $22(36.67 \%)$ of studied patients. Twenty-one (35.00\%) of the patients had focal segmental GS. We reported that there were $20(33.33 \%)$ of the children who had stage 3 (A and B) and $40(66.67 \%)$ had stage 4 (Table 2).

Thirty-two $(53.33 \%)$ of the studied patients had normal diastolic function (group A) while 28 (46.67\%) had grade II diastolic dysfunction (group B).

Diastolic dysfunction observed in the children with CKD was evidenced by a lower $E^{\prime}$ and a higher $E / E^{\prime}$ ratio.

Comparing group A with group $\mathrm{B}$, there was statistically significant difference in mean $E / E^{\prime}$ ( $p$ value $\left.<0.0001\right)$, mitral $E$ velocity $(p$ value $=0.009)$, lateral mitral annulus $E^{\prime}$ ( $p$ value $<0.0001$ ), septal mitral annulus $E^{\prime}$ ( $p$ value $\left.<0.0001\right)$; meanwhile, there was no statistically significant difference in mitral valve $E / A$ ratio $(p$ value $=0.89)$ (Table 3$)$.

Comparing group A with group B as regards the demographic data and anthropometric measurements revealed that there was no statistically significant difference in age $(p$ value $=0.58)$, gender $(p$ value $=0.58)$, consanguinity ( $p$ value $=0.18)$, weight $(p$ value $=0.93)$, height $(p$ value $=0.77)$, and body mass index $(p$ value $=0.89)$ Table 4 . 
TABLE 6: The relation between diastolic dysfunction and lab investigation of children with CKD.

\begin{tabular}{|c|c|c|c|}
\hline Variable & $\begin{array}{c}\text { Group A } \\
N=32\end{array}$ & $\begin{array}{c}\text { Group B } \\
N=28\end{array}$ & $p$ value \\
\hline \multicolumn{4}{|l|}{$W B C s$} \\
\hline Mean \pm SD & $8.18 \pm 1.29$ & $8.59 \pm 2.20$ & 0.38 \\
\hline Median (range) & $8(5.8: 11.6)$ & $8.05(5.3: 14.9)$ & \\
\hline \multicolumn{4}{|l|}{$H B$} \\
\hline Mean \pm SD & $10.01 \pm 1.12$ & $10.56 \pm 1.08$ & 0.06 \\
\hline Median (range) & $10.05(7.4: 13)$ & $10.5(8.6: 13.4)$ & \\
\hline \multicolumn{4}{|c|}{ Anemia $(H B<11 \mathrm{gm} / \mathrm{dl})$} \\
\hline No & $8(25.00 \%)$ & $7(25.00 \%)$ & 1.00 \\
\hline Yes & $24(75.00 \%)$ & $21(75.00 \%)$ & \\
\hline \multicolumn{4}{|l|}{ HCT } \\
\hline Mean \pm SD & $29.20 \pm 5.77$ & $30.75 \pm 4.27$ & 0.24 \\
\hline Median (range) & $30.95(19: 38.4)$ & $31.75(19.5: 36.8)$ & \\
\hline \multicolumn{4}{|l|}{$M C V$} \\
\hline Mean \pm SD & $75.41 \pm 6.60$ & $75.95 \pm 4.64$ & 0.72 \\
\hline Median (range) & $75.25(65: 96.6)$ & $77(63: 88.6)$ & \\
\hline \multicolumn{4}{|l|}{ PLTs } \\
\hline Mean \pm SD & $294.63 \pm 82.72$ & $276.79 \pm 102.27$ & 0.20 \\
\hline Median (range) & $296(156: 450)$ & $274(134: 614)$ & \\
\hline \multicolumn{4}{|l|}{ Serum creatinine } \\
\hline Mean \pm SD & $2.59 \pm 0.92$ & $2.24 \pm 0.86$ & 0.14 \\
\hline Median (range) & $2.5(1.1: 4.4)$ & $1.9(1.1: 4.7)$ & \\
\hline \multicolumn{4}{|l|}{$\mathrm{Ca}$} \\
\hline Mean \pm SD & $8.29 \pm 0.61$ & $7.55 \pm 0.63$ & $<0.0001$ \\
\hline Median (range) & $8.35(6.8: 9.5)$ & $7.35(6.7: 8.8)$ & \\
\hline \multicolumn{4}{|l|}{ Phosphorus } \\
\hline Mean \pm SD & $4.78 \pm 0.85$ & $6.70 \pm 1.29$ & $<0.0001$ \\
\hline Median (range) & $4.4(4.1: 7.3)$ & $6.8(4.8: 9.1)$ & \\
\hline \multicolumn{4}{|l|}{ PTH } \\
\hline Mean \pm SD & $240.1 \pm 124.44$ & $532.91 \pm 120.54$ & $<0.0001$ \\
\hline Median (range) & $210.05(148.7: 767.5)$ & $521(387.5: 832.5)$ & \\
\hline \multicolumn{4}{|c|}{$25(\mathrm{OH})$ cholecalciferol } \\
\hline Mean \pm SD & $15.70 \pm 3.02$ & $11.74 \pm 2.68$ & $<0.0001$ \\
\hline Median (range) & $15.8(10: 21.5)$ & $11.6(6.02: 17.1)$ & \\
\hline \multicolumn{4}{|c|}{$25(\mathrm{OH})$ cholecalciferol } \\
\hline$>15 \mathrm{ng}$ & $18(56.25 \%)$ & $3(10.71 \%)$ & $<0.0001$ \\
\hline$<15 \mathrm{ng}$ & $14(43.75 \%)$ & $25(89.29 \%)$ & \\
\hline
\end{tabular}

Comparing group A with group B, there was no statistically significant difference in the causes of CKD ( $p$ value $=$ 0.997 ) and GFR ( $p$ value $=0.2)$, while there is statistically significant difference in stages of CKD $(p$ value $=0.03)$. There were 24 of the studied patients in group B who were hypertensive $(p$ value $=0.002)$ (Table 5$)$.

As regards laboratory finding in group A and group B, there was no statistically significant difference in WBCs ( $p$ value $=0.38), \mathrm{Hb}(p$ value $=0.06), \operatorname{PLTs}(p$ value $=0.2)$, and serum creatinine $(p$ value $=0.14)$ (Table 6$)$.

Vitamin D deficiency was prevalent in children with CKD. The mean 25-hydroxy vitamin $\mathrm{D}$ level in a group $\mathrm{A}$ was $15.70 \pm 3.02$ while in a group $B$ was $11.74 \pm 2.68$ ( $p$ value $<0.0001)$. When the cases were subdivided into two groups using a cutoff value of $15 \mathrm{ng} / \mathrm{ml}$ for the mean 25-hydroxy vitamin $\mathrm{D}$ level, we found the higher proportion in group $\mathrm{B}$ 
was 25 (89.29\%) while in group A was 14 (43.75\%); this was found to be statistically significant ( $p$ value $<0.0001$ ). The mean level of serum phosphorus in group $\mathrm{A}$ was $4.78 \pm$ 0.85 while in group B was $6.70 \pm 1.29$; this was found to be statistically significant ( $p$ value $<0.0001$ ). The mean serum levels of intact PTH in group A was 240.1 \pm 124.44 while in group $\mathrm{B}$ was $532.91 \pm 120.54$; this was found to be statistically significant $(p$ value $<0.0001$ ) (Figures $1-3$ and Tables 6 and 7).

Multivariate logistic regression of factors that may affect diastolic dysfunction revealed that there was no statistically significant in stages of CKD ( $p$ value $=0.07)$, serum $\mathrm{Ca}(p$ value $=0.82)$, and serum $25(\mathrm{OH})$ cholecalciferol $(p$ value $=$ $0.59)$ while there was statistical significance in serum phosphorus $(p$ value $=0.03)$, serum PTH $(p$ value $=0.002)$, and hypertension $(p$ value $=0.03)$ (Table 8$)$.

By correlation coefficient test $(r)$, there was statistically significant positive correlation between LVMI and iPTH level $\quad(r=0.89, \quad p \leq 0.0001), \quad 25(\mathrm{OH}) \quad$ cholecalciferol $(r=-0.27, p=0.04)$, serum Ca $(r=-0.37, p=0.004)$, and serum phosphorus $(r=-0.45, p=0.0003)$ (Table 9).

\section{Discussion}

Some studies have suggested the progression of CKD, and the associated cardiovascular diseases may be linked to vitamin D insufficiency or deficiency $[18,19]$. However, our study demonstrated that there was no correlation with vitamin $\mathrm{D}$ deficiency while the serum PTH levels significantly correlated with diastolic dysfunction of the studied children as evidenced by their echocardiographic data, $E / E^{\prime}$ ratio.

The number of cases in this cohort study was 60 patients with CKD (stage 3 or 4 ); they were $32(53.33 \%)$ males and 28 $(46.67 \%)$ females, the median age of children was 7 (2:13), the median weight was $18(8: 39)$ while the median height was $113.5(79: 148)$ when compared to EL-Gamasy et al.'s [12] study, where the number of cases was 86 with CKD (stage 4 or 5), they were 48 (55.8\%) males and 38 (44.2\%) females, their age of them ranged from 10 to 18 years with a mean value of $13.7 \pm 3.9$ years, and the number of control was 40 .

In Patange et al. [13], the number of cases was 34 children with CKD, 20 were receiving dialysis, and 14 were not receiving any form of dialysis for the management of CKD, 19 (55.9\%) males, and 15 (44.1\%) females; their mean age $14.7 \pm 2.6$.

Our results had reported that the most common causes of CKD were congenital renal anomalies 22 (36.67\%); incomparable with EL-Gamasy et al. [12], the most common causes were difficult to treat nephrotic syndrome 44 (51.2\%).

We had reported that the number of cases that had normal diastolic function was 32 (53.33\%), while those had diastolic dysfunction were 28 (46.67\%), in concordance with ELGamasy et al.'s study [12].

In the present study, the anthropometric measurements in group A (normal diastolic function) and group B (grade II diastolic dysfunction) were no statistically significant difference in age ( $p$ value $=0.58)$, gender $(p$ value $=0.58)$, con-

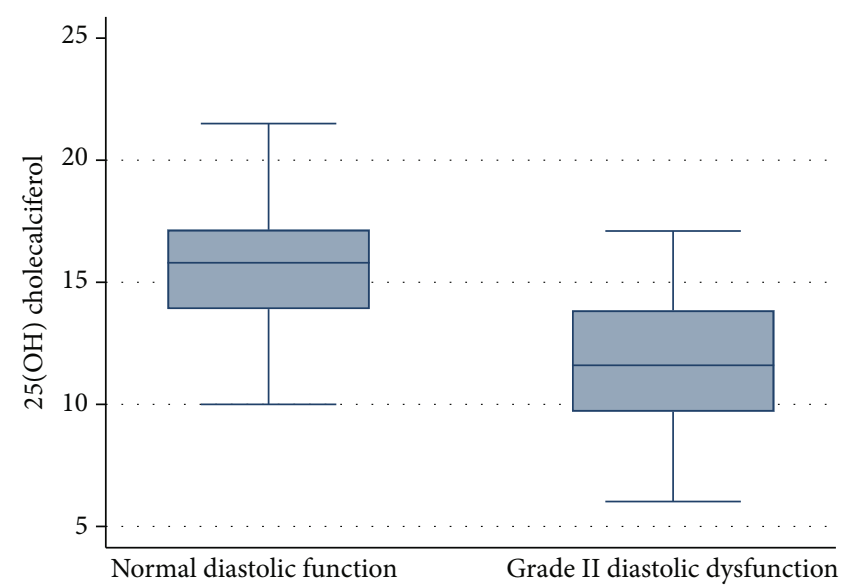

FIgURE 1: The relation between diastolic dysfunction and $25(\mathrm{OH})$ cholecalciferol.

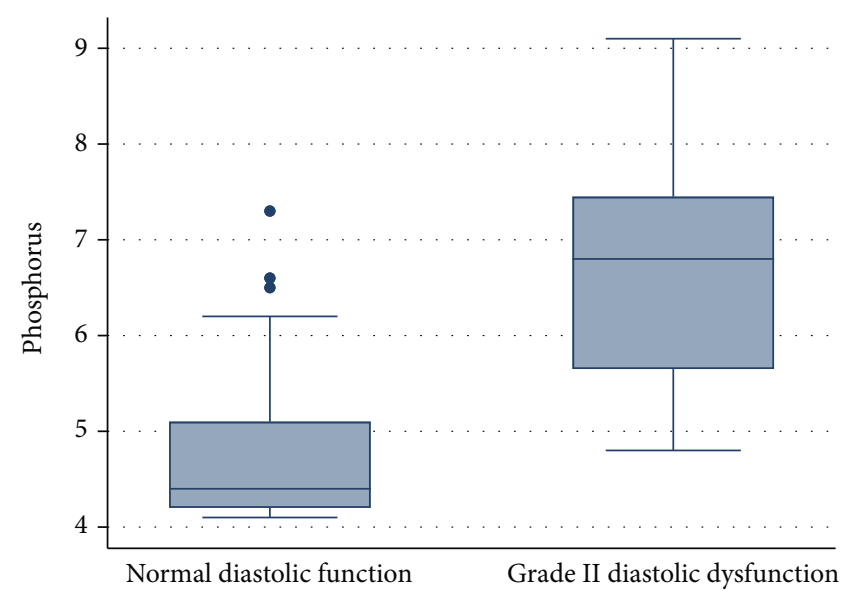

FIgure 2: The relation between diastolic dysfunction and phosphorus.

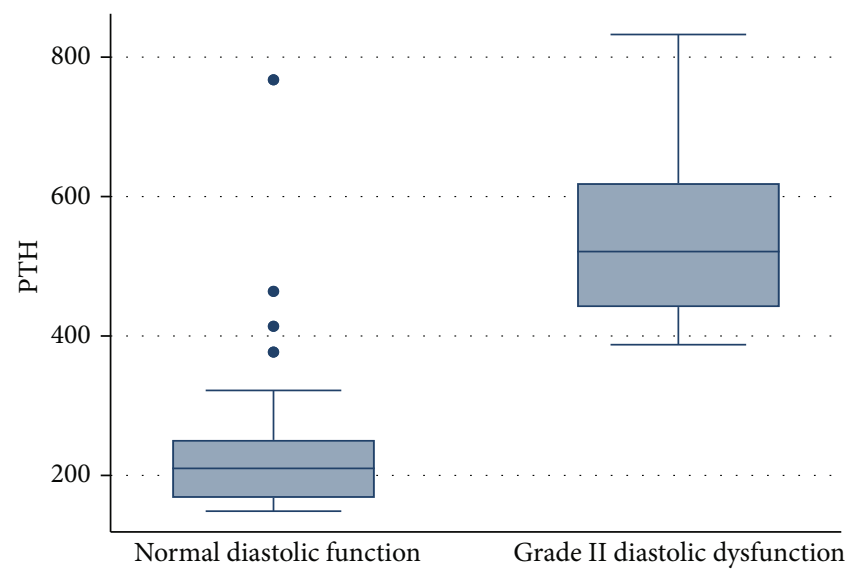

FIgURE 3: Relation between diastolic dysfunction and parathyroid hormone.

sanguinity $(p$ value $=0.18)$, weight $(p$ value $=0.93)$, height $(p$ value $=0.77)$, and body mass index $(p$ value $=0.89)$ which was in agreement with the results found in EL-Gamasy et al.'s [12] study where there was no statistically significant 
TABLE 7: The relation between indices of diastolic function, serum Ca, serum phosphorus, serum PTH, and serum 25(OH) cholecalciferol.

\begin{tabular}{|c|c|c|c|}
\hline Cardiovascular outcomes of interest & Significant predictors at univariate analysis & Correlation coefficient $(r)$ & $p$ value \\
\hline \multirow{4}{*}{ Mean $E / E^{\prime}$} & PTH & 0.63 & $<0.0001$ \\
\hline & $25(\mathrm{OH})$ cholecalciferol & -0.48 & 0.0001 \\
\hline & $\mathrm{Ca}$ & -0.53 & $<0.0001$ \\
\hline & Phosphorus & 0.61 & $<0.0001$ \\
\hline \multirow{4}{*}{ Lateral mitral annulus $E^{\prime}$} & PTH & -0.38 & 0.003 \\
\hline & $25(\mathrm{OH})$ cholecalciferol & 0.18 & 0.018 \\
\hline & $\mathrm{Ca}$ & 0.55 & $<0.0001$ \\
\hline & Phosphorus & -0.55 & $<0.0001$ \\
\hline \multirow{4}{*}{ Septal mitral annulus $E^{\prime}$} & PTH & -0.36 & 0.004 \\
\hline & $25(\mathrm{OH})$ cholecalciferol & 0.23 & 0.07 \\
\hline & $\mathrm{Ca}$ & 0.43 & 0.0006 \\
\hline & Phosphorus & -0.49 & 0.00001 \\
\hline
\end{tabular}

TABle 8: Multivariate logistic regression of factors that may affect diastolic dysfunction.

\begin{tabular}{lcc}
\hline Variable & $\begin{array}{c}\text { Odds ratio }(95 \% \text { confidence } \\
\text { interval }\end{array}$ & $\begin{array}{c}p \\
\text { value }\end{array}$ \\
\hline $\begin{array}{l}\text { Stages of CKD } \\
\text { Stage } 3 \mathrm{~A} / \mathrm{B}\end{array}$ & 1 & \\
Stage $4 / 5$ & $0.14(0.02: 1.13)$ & 0.07 \\
\hline Ca & $0.70(0.04: 13.5)$ & 0.82 \\
Phosphorus & $7.26(1.22: 43.34)$ & 0.03 \\
PTH & $1.02(1.01: 1.03)$ & 0.002 \\
$25($ OH) & & \\
cholecalciferol & 1 & \\
$>15 \mathrm{ng}$ & $1.74(0.23: 13.32)$ & 0.59 \\
$<15 \mathrm{ng}$ & $19.79(1.46: 267.44)$ & 0.03 \\
Hypertension & & \\
\hline
\end{tabular}

difference in age $(p$ value $=0.46)$ and gender $(p$ value $=0.29)$. In Patange et al. [13], the same results were found where there was no statistically significant difference in age, gender, and BMI ( $p$ value not significant).

We observed that there was no statistically significant difference between two groups in the causes of CKD ( $p$ value $=$ 0.997 ) and GFR ( $p$ value $=0.2$ ), while there statistically significant difference in stages of CKD $(p$ value $=0.03)$ which was in agreement with EL-Gamasy et al.'s [12] study where there was no statistically significant difference in causes ( $p$ value $=$ 0.09 ) and GFR ( $p$ value > 0.05).

The results of the present study revealed that $39(65 \%)$ of the studied patients had hypertension, 24 (85.71\%) had grade II diastolic dysfunction, 15 (46.88\%) had normal diastolic function $(p$ value $=0.002)$, which was in agreement with EL-Gamasy et al.'s [12] study, 53 (61.6\%) of the studied patients were hypertensive ( $p$ value $<0.001)$, and the same results were found in Patange et al. [13] study where there were $28(82.4 \%)$ of the studied patient who were hypertensive $(p$ value $\otimes 0.05)$. Hypertension is an independent common risk factor for cardiovascular diseases in children with CKD.

The current study had shown that the laboratory finding in group A and group B was no statistically significant difference in WBCs $(p$ value $=0.38)$, Hb $(p$ value $=0.06)$, PLTs $(p$ value $=0.2)$, and serum creatinine $(p$ value $=0.14)$ that was not in agreement with EL-Gamasy et al. [12] that had been reported that there was no statistically significant difference in serum creatinine ( $p$ value $>0.05$ ), but there was a statistically significant difference in $\mathrm{Hb}(p$ value $=0.0002)$.

Our results revealed the mean level of serum phosphorus in group A was $4.78 \pm 0.85$ while in group B was $6.70 \pm 1.29$ ( $p$ value $<0.0001)$

Hyperphosphatemia was correlated with indices of diastolic dysfunction as evidenced by the echocardiographic data, mean $E / E^{\prime}(r=0.61, p$ value $<0.0001)$, lateral mitral annulus $E^{\prime}(r=-0.55, p$ value $<0.0001)$, and septal mitral annulus $E^{\prime}(r=-0.49, p$ value $=0.00001)$. We demonstrated that hyperphosphatemia was considered a significant risk factor for the development of diastolic dysfunction in cases with CKD.

This was in agreement with EL-Gamasy et al.'s [12] study which had reported a mean level of serum phosphate of 7.3 $\pm 2.4 \mathrm{mg} / \mathrm{dl}$ and $5.5 \pm 1.4 \mathrm{mg} / \mathrm{dl}$ in cases with and without diastolic dysfunction.

Also, our study agreed with Mahdi et al. [14] study who emphasized that hyperphosphatemia that promotes loss of minerals from bone can also promote metastatic or vascular calcification.

Galetta et al. [15] study also demonstrated a statistically significant positive correlation between hyperphosphatemia and increased CVD in their uremic patients on maintenance hemodialysis.

Furthermore, our results show that the mean serum levels of intact PTH in group A was $240.1 \pm 124.44$ while in group B was $532.91 \pm 120.54$; this was found to be statistically significant ( $p$ value $<0.0001)$. Hyperparathyroidism was correlated with indices of diastolic dysfunction as evidenced by the echocardiographic data, mean $E / E^{\prime}(r=0.63, p$ value $<0.0001)$, 
TABLE 9: The relation between left ventricular mass index, serum Ca, serum phosphorus, serum PTH, and 25(OH) cholecalciferol.

\begin{tabular}{|c|c|c|c|}
\hline Cardiovascular outcomes of interest & Significant predictors at univariate analysis & Correlation coefficient $(r)$ & $p$ value \\
\hline \multirow{4}{*}{ Left ventricular mass index } & PTH & 0.89 & $<0.0001$ \\
\hline & $25(\mathrm{OH})$ cholecalciferol & -0.27 & 0.04 \\
\hline & $\mathrm{Ca}$ & -0.37 & 0.004 \\
\hline & Phosphorus & 0.45 & 0.0003 \\
\hline
\end{tabular}

lateral mitral annulus $E^{\prime}(r=-0.38, p$ value $=0.003)$, and septal mitral annulus $E^{\prime}(r=-0.36, p$ value $=0.004)$. Hence, we reported that hyperparathyroidism was a significant risk factor for the development of diastolic dysfunction in cases with CKD.

Our results were in agreement with Patange et al. [13] who reported that in their study of 34 pediatric patients with CKD, the serum PTH levels correlated with diastolic dysfunction of their studied children as evidenced by their echocardiographic data, $E / E^{\prime}$ ratio $(r=0.6, p<0.05)$ and $E^{\prime}$ $(r=-0.6, p$ value $<0.05)$.

Strózecki et al.'s study was in accordance to our results which had reported increased serum phosphate level in CKD which is predisposing to the development of secondary hyperparathyroidism and to elevated $\mathrm{Ca}$ xPo4 leading to extravascular metastatic calcification. Both conditions involved in cardiac morbidity and mortality in CKD [16].

Hypovitaminosis D was found in both group A and group B. The mean 25-hydroxy vitamin $\mathrm{D}$ level in group $\mathrm{A}$ was $15.70 \pm 3.02$ while in group B was $11.74 \pm 2.68$, respectively. Notably, the interrelations among variables and multivariate logistic regression of factors revealed that hyperphosphatemia, hyperparathyroidism, and hypertension were the most risk factors to have a serious hazardous impact on left ventricular function especially diastolic dysfunction.

The results of our study were in accordance to which reported by EL-Gamasy et al. [12] who demonstrated that there was no statistically significant association between vitamin D deficiency and diastolic dysfunction in CKD patients $(p=0.3$ ), which also was following the report by Pandit et al. [17].

Our results were not in agreement with Patange et al.'s [13] study which emphasized that hyperparathyroidism was linked to diastolic dysfunction suggesting the increased PTH level observed in children with CKD was secondary to chronic vitamin D deficiency, thus supposed that the diastolic dysfunction was linked to vitamin D deficiency as well.

Our study encompassed the correlation coefficient test $(r)$ which confirmed a statistically significant positive correlation between LVMI and iPTH level $(r=0.89, p \leq 0.0001)$ that was in agreement with EL-Gamasy et al.'s [12] study who reported that there was a statistically significant between iPTH and LVMI $(r=0.47, p<0.05)$. Furthermore, Al-Hilali et al.'s [18] study found a positive correlation between iPTH and LVMI in their study on their patients on hemodialysis.

We demonstrated a positive correlation between $25(\mathrm{OH})$ cholecalciferol and LVMI $(r=-0.27$, $p$ value $=0.04)$; this was in agreement with Patange et al.'s [13] study of 34 children with CKD that showed that LVMI inversely correlated with vitamin $\mathrm{D}$, and it was also statistically significant $(r=-0.5$; $p<0.05)$. Meanwhile, EL-Gamasy et al.'s [12] study had not been reported any significant correlation between $25(\mathrm{OH})$ cholecalciferol and LVMI $(r=-0.02, p>0.05)$.

\section{Study Limitation}

Limitations of the present study include small cohort pediatric patients. The tissue Doppler indicators of diastolic dysfunction were not normalized to age-independent $z$-score. Another obvious limitation of our study is the crosssectional design of our analysis, not a case-control one.

\section{Conclusion}

Our results emphasized that hyperparathyroidism, hyperphosphatemia, and hypertension are significantly associated with diastolic dysfunction while hypovitaminosis D was not significantly associated. Vitamin D deficiency was prevalent in all children with CKD. Biomarkers of mineral bone density were significantly associated with left ventricular hypertrophy and increased left ventricular mass index.

\section{Data Availability}

The data will be available on request through a data access committee, institutional review board, or the authors themselves.

\section{Conflicts of Interest}

The authors declare that they have no conflicts of interest.

\section{References}

[1] N. R. Hill, S. T. Fatoba, J. L. Oke et al., "Global prevalence of chronic kidney disease - a systematic review and meta-analysis," PLoS One, vol. 11, no. 7, article e0158765, 2016.

[2] Kidney Disease, "Improving Global Outcomes (KDIGO) CKD workgroup. KDIGO 2012 clinical practice guideline for the evaluation and management of chronic kidney disease," Kidney International Supplements, vol. 3, pp. 1-150, 2013.

[3] R. Parekh, C. Carroll, R. Wolfe, and F. K. Port, "Cardiovascular mortality in children and young adults with end-stage kidney disease," The Journal of Pediatrics, vol. 141, no. 2, pp. 191197, 2002.

[4] P. Haciomeroglu, O. Ozkaya, N. Gunal, and K. Baysal, "An echocardiographic assessment of cardiac functions and structure in children on dialysis," Renal Failure, vol. 30, no. 2, pp. 147-153, 2008.

[5] Y. T. Lindblad, J. Axelsson, R. Balzano et al., "Left ventricular diastolic dysfunction by tissue Doppler echocardiography in 
pediatric chronic kidney disease," Pediatric Nephrology, vol. 28, no. 10, pp. 2003-2013, 2013.

[6] C. Rinat, R. Becker-Cohen, A. Nir et al., "A comprehensive study of cardiovascular risk factors, cardiac function and vascular disease in children with chronic renal failure," Nephrology, Dialysis, Transplantation, vol. 25, no. 3, pp. 785-793, 2010.

[7] J. Artaza, R. Mehrotra, and K. Norris, "Vitamin D and the cardiovascular system," Clinical Journal of the American Society of Nephrology, vol. 4, no. 9, pp. 1515-1522, 2009.

[8] A. Cardús, E. Parisi, C. Gallego, M. Aldea, E. Fernández, and J. M. Valdivielso, "1,25-Dihydroxyvitamin $\mathrm{D}_{3}$ stimulates vascular smooth muscle cell proliferation through a VEGFmediated pathway," Kidney International, vol. 69, no. 8, pp. 1377-1384, 2006.

[9] G. Schwartz, G. Haycock, C. M. Edelmann Jr., and A. Spitzer, "A simple estimate of glomerular filtration rate in children derived from body length and plasma creatinine," Pediatrics, vol. 58, no. 2, pp. 259-263, 1976.

[10] G. de Simone, S. Daniels, R. B. Devereux et al., "Left ventricular mass and body size in normotensive children and adults: assessment of allometric relations and impact of overweight," Journal of the American College of Cardiology, vol. 20, no. 5, pp. 1251-1260, 1992.

[11] B. W. Eidem, C. J. McMahon, N. A. Ayres et al., "Impact of chronic left ventricular preload and afterload on Doppler tissue imaging velocities: a study in congenital heart disease," Journal of the American Society of Echocardiography, vol. 18, no. 8, pp. 830-838, 2005.

[12] M. El-Gamasy, W. El-Shehaby, and M. Mabrouk, "Early predictors of cardiac dysfunction in Egyptian children with chronic kidney disease," Annals of Pediatric Cardiology, vol. 12, no. 1, pp. 10-17, 2019.

[13] A. Patange, R. Valentini, M. Gothe, W. Du, and M. D. Pettersen, "Vitamin D deficiency is associated with increased left ventricular mass and diastolic dysfunction in children with chronic kidney disease," Pediatric Cardiology, vol. 34, no. 3, pp. 536-542, 2013.

[14] A. Mahdi, R. Brown, and M. Razzaque, "Osteoporosis in populations with High calcium intake: does phosphate toxicity explain the paradox?," Indian Journal of Clinical Biochemistry, vol. 30, no. 4, pp. 365-367, 2015.

[15] F. Galetta, A. Cupisti, F. Franzoni et al., "Left ventricular function and calcium phosphate plasma levels in uraemic patients," Journal of Internal Medicine, vol. 258, no. 4, pp. 378-384, 2005.

[16] P. Stróżecki, A. Adamowicz, E. Nartowicz, G. Odrowąż-Sypniewska, Z. Włodarczyk, and J. Manitius, "Parathormon, calcium, phosphorus, and left ventricular structure and function in normotensive hemodialysis patients," Renal Failure, vol. 23, no. 1, pp. 115-126, 2001.

[17] A. Pandit, F. Mookadam, S. Boddu et al., "Vitamin D levels and left ventricular diastolic function," Open Heart, vol. 1, no. 1, article e000011, 2014.

[18] N. al-Hilali, N. Hussain, A. Ataia, M. al-Azmi, B. al-Helal, and K. V. Johny, "Hypertension and hyperparathyroidism are associated with left ventricular hypertrophy in patients on hemodialysis," Indian Journal of Nephrology, vol. 19, no. 4, pp. 153-157, 2009.

[19] A. Vivante and F. Hildebrandt, "Exploring the genetic basis of early-onset chronic kidney disease," Nature Reviews. Nephrology, vol. 12, no. 3, pp. 133-146, 2016. 